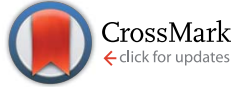

Cite this: RSC Adv., 2015, 5, 83504

Received 7th July 2015

Accepted 28th September 2015

DOI: $10.1039 / \mathrm{c} 5 \mathrm{ra13305j}$

www.rsc.org/advances

\section{Magnetic and optical properties of Fe doped crednerite $\mathrm{CuMnO}_{2}$}

\author{
Kaushal K. Shukla, ${ }^{a}$ P. Shahi, ${ }^{a}$ Gopal S., ${ }^{\text {b }}$ A. Kumar, ${ }^{a}$ A. K. Ghosh, ${ }^{c}$ Ripandeep Singh, ${ }^{d}$ \\ Neetika Sharma, ${ }^{d}$ A. Das, ${ }^{d}$ A. K. Sinha, ${ }^{e}$ Amish G. Joshi, ${ }^{f}$ A. K. Nigam ${ }^{g}$ \\ and Sandip Chatterjee ${ }^{\star a}$
}

A geometrically frustrated magnetic $\mathrm{CuMnO}_{2}$ system has been investigated because of its rich magnetic properties. Neutron diffraction, synchrotron X-ray, magnetic, X-ray photoemission spectroscopy (XPS) and UV-Visible spectroscopy measurements have been carried out on $\mathrm{CuMnO}_{2}$ and $5 \% \mathrm{Fe}$ doped $\mathrm{CuMnO}_{2}$ samples. Fe doping reduces the distortion. Moreover, Fe doping induces the ferromagnetic coupling between ab planes. The value of magnetization is increased with Fe doping but coercivity is decreased. These might be due to the direct $\mathrm{Mn}-\mathrm{Mn}$ exchange and $\mathrm{Mn}-\mathrm{O}-\mathrm{Cu}-\mathrm{O}-\mathrm{Mn}$ super-super exchange interactions. The UV-Vis data indicate the appearance of new energy bands in these compounds. The XPS study indicates that Fe is in the $3+$ state.

\section{Introduction}

Geometrically frustrated magnetic systems have attracted much attention due to their interesting magnetic properties. ${ }^{1-3}$ In these systems, spin ordering is suppressed by competing exchange interactions well below the Curie temperature. $A B \mathrm{O}_{2}$-type triangular-lattice antiferromagnets in which not all the interactions are minimized simultaneously, are popular examples of geometrically frustrated systems. ${ }^{4-7}$ Crednerite $\mathrm{CuMnO}_{2}$ is an $A B \mathrm{O}_{2}$-type triangular-lattice antiferromagnet. The crystal structure of $\mathrm{CuMnO}_{2}$ contains of isosceles-triangular lattices of $\mathrm{Mn}$. It has a monoclinic structure with $C 2 / m$ space group; it is distorted from the hexagonal delafossite structure because of Jahn-Teller effect of $\mathrm{Mn}^{3+}$ ions that have crystal-field splitting in $\mathrm{e}_{\mathrm{g}}$ orbitals due to $\mathrm{d}^{4}$ electronic configuration. Moreover, different directions in the triangular $a b$ plane become inequivalent: for each $\mathrm{Mn}$, two short and four long $\mathrm{Mn}-\mathrm{Mn}$ distances exist. It is observed that the exchange interaction at short bonds is stronger, which, with the uniaxial magnetic anisotropy of $\mathrm{Mn}^{3+}$ (spins are oriented predominantly along the long $\mathrm{Mn}-\mathrm{O}$ bonds), leaves the system frustrated. This degeneracy is lifted below magnetic transition:

\footnotetext{
${ }^{a}$ Department of Physics, Indian Institute of Technology (Banaras Hindu University), Varanasi-221005, India. E-mail: schatterji.app@iitbhu.ac.in

${ }^{b}$ School of Material Science \& Technology, Indian Institute of Technology, (Banaras Hindu University), Varanasi 221005, India

'Department of Physics, Banaras Hindu University, Varanasi 221005, India

${ }^{d}$ Solid State Physics Division, Bhabha Atomic Research Centre, Mumbai 400085, India 'Indus Synchrotrons Utilization Division, Raja Ramanna Centre for Advanced Technology, Indore 452013, India

${ }^{f}$ CSIR-National Physical laboratory, Dr. K.S. Krishnan Road, New Delhi 110 012, India ${ }^{g}$ Department of CMP \& MS Tata Institute of Fundamental Research, Mumbai, 400005, India
}

at $T<T_{\mathrm{N}}=65 \mathrm{~K}$ and the structure changes from monoclinic to triclinic (space group C1) due to magnetostriction. ${ }^{8}$ Recently, Ushakov et al. have shown that the presence of ferro-orbital ordering in $\mathrm{Cu}_{1+x} \mathrm{Mn}_{1-x} \mathrm{O}_{2}$ plays a very important role in determining the exchange constants and the magnetic structure. ${ }^{9}$

Furthermore, in nonstoichiometric crednerite with a small excess of copper $\left(\mathrm{Cu}_{1.04} \mathrm{Mn}_{0.96} \mathrm{O}_{2}\right)$, the in plane magnetic ordering remains practically the same as for pure $\mathrm{CuMnO}_{2}$, the interlayer exchange coupling changes from antiferromagnetic in $\mathrm{CuMnO}_{2}$ to ferromagnetic in $\mathrm{Cu}_{1.04} \mathrm{Mn}_{0.96} \mathrm{O}_{2}$ and vice versa. ${ }^{10}$ Recent neutron diffraction studies have revealed the magnetic structure of $\mathrm{CuMnO}_{2}$ and the crystal structure deformation associated with the magnetic ordering., ${ }^{8,11}$ The magnetic structure below $T_{\mathrm{N}}=$ $65 \mathrm{~K}$ is the collinear one with the magnetic propagation vector $\boldsymbol{k}_{1}=(1 / 2 \cdot 1 / 2 \cdot 1 / 2)$. In addition to $\boldsymbol{k}_{1}$, they observed the other group of the magnetic Bragg reflections which are assigned by $\boldsymbol{k}_{2}$ $=(1 / 2 \cdot 1 / 2 \cdot 0)$. While the intensity for $\boldsymbol{k}_{1}$ is dominant, that for $\boldsymbol{k}_{2}$ is speculated to be caused by a small amount of impurity of $\mathrm{Cu}_{1+x} \mathrm{Mn}_{1-x} \mathrm{O}_{2} .{ }^{8}$ Trari et al. ${ }^{12}$ reported the magnetic susceptibility of $\mathrm{Cu}_{1+x} \mathrm{Mn}_{1-x} \mathrm{O}_{2}$ (with $x=0-0.2$ ), suggesting that the magnetic susceptibility is highly sensitive to the atomic disorders. However, the minor fraction for $\boldsymbol{k}_{2}$ has not been investigated thus far. The structural phase transition also occurs below $T_{\mathrm{N}}$ from the monoclinic $C 2 / m$ to the triclinic $C \overline{1}$ in $\mathrm{CuMnO}_{2}{ }^{8,11}$ The degeneracy in the exchange interaction paths between base sites and apex sites in isosceles triangular lattice, $J_{2}$, is lifted by the distortion. It is evident from these previous studies that interlayer coupling plays a significant role in the long range magnetic ordering in $\mathrm{CuMnO}_{2}$, and that this can be characterised using neutron diffraction. There is some dispute, however, over the source of the $\boldsymbol{k}_{2}$ ordering as to whether it is intrinsic to the structure or a result of some impurity. In this study, we have thus 
doped Fe into the $\mathrm{Mn}$ site in $\mathrm{CuMnO}_{2}$ so as to examine the effects on the inter-layer coupling and on this ordering.

\section{Experimental}

The $\mathrm{CuMn}_{1-x} \mathrm{Fe}_{x} \mathrm{O}_{2}$ (with $x=0.0$ and 0.05 ) samples were prepared by solid state reaction in an evacuated quartz tube. Powders $\mathrm{CuO}, \mathrm{MnO}$ and $\mathrm{Fe}_{2} \mathrm{O}_{3}$ were mixed in appropriate ratio and pressed into pellets. The pellets were then placed in an alumina crucible, sealed in quartz tube under high vacuum $\left(\sim 10^{-6} \mathrm{mbar}\right)$ and heated at $950^{\circ} \mathrm{C}$ for $12 \mathrm{~h}$. Powder XRD data were recorded using ADXRD beam line (on bending magnet port BL-12) of the Indus-2 (2.5 GeV, $100 \mathrm{~mA})$ synchrotron radiation (SR) source at Raja Ramanna Centre for Advanced Technology (RRCAT), Indore, India. The diffraction data were collected on a image plate (mar 345) detector. The diffraction images were integrated using FIT2D program. Wave length and sample to detector distance were accurately calibrated using XRD pattern of $\mathrm{LaB}_{6}$ NIST standard. Neutron powder diffraction (NPD) patterns were recorded on the PD2 diffractometer $(\lambda=$ $1.2443 \AA$ ) at Bhabha Atomic Research Centre, Mumbai, India. The observed XRD and neutron powder diffraction patterns were analyzed by Rietveld method using the Fullprof-2K software package. The basis vector for the magnetic refinement was determined using BASIREPS program. Magnetic measurements were carried out using MPMS, SQUID (Quantum Design) magnetometer with the bulk samples. Data were collected during warm up cycle. The absorption spectra were measured in the range of $200-800 \mathrm{~nm}$ using UV-Vis spectrometer. X-ray Photoelectron Spectroscopy (XPS) experiments were performed using Omicron Nanotechnology UHV system equipped with a twin anode $\mathrm{Mg} / \mathrm{Al}$ X-ray source (DAR400), a monochromatic source (XM 1000) and a hemispherical electron energy analyzer (EA125). All the XPS measurements were performed inside the analysis chamber under average base vacuum of $8.1 \times 10^{-10}$ Torr using monochromatized AlK $\alpha$ at $15 \mathrm{kV}$ and 300 watt. The total energy resolution, estimated from the width of the Fermi energy, was about $250 \mathrm{meV}$ for monochromatic AlK $\alpha$ line with photon energy $1486.7 \mathrm{eV}$. During photoemission studies, small specimen charging was observed which was later calibrated by assigning the C1s signal at $284.6 \mathrm{eV}$. Resistivity measurements have been performed by four probe method.

\section{Results and discussions}

\section{Structural characterization}

The results of the refinements using Synchrotron X-ray diffraction data and neutron diffraction data are shown in Fig. 1 and 2 (room temperature), and Tables 1 and 2, respectively. These show good agreement with previously reported data for the crednerite structure of $\mathrm{CuMnO}_{2} \cdot{ }^{13,14}$ The cell volume of $\mathrm{CuMn}_{0.95} \mathrm{Fe}_{0.05} \mathrm{O}_{2}\left(92.1062 \AA^{3}\right)$ is slightly larger than that of $\mathrm{CuMnO}_{2}\left(91.9023 \AA^{3}\right)$; it corresponds mainly to a decrease of $a$, an increase of the $\beta$ angle, and a small increase of $b$ and $c$. The changes in the $\beta$ angle, $a$ and $b$ parameters will have effects on the exchange interactions between $a b$ planes and in the basal plane, respectively. In the same way, the dilution on the Mn site, because of the small substitution of $\mathrm{Fe}$ for $\mathrm{Mn}$, induces a smaller ( $\mathrm{Mn} / \mathrm{Fe}-\mathrm{O})$ average distance 2.0446(3) $\AA$ compared to 2.0451(5) $\AA$ for $\mathrm{CuMnO}_{2}$ and a smaller Jahn-Teller distortion of the $\mathrm{MnO}_{6}$ octahedra (by comparing the $\delta=d(\mathrm{Mn}-\mathrm{O})$ apical/ $d(\mathrm{Mn}-\mathrm{O})$ equatorial). The irregularity in the triangular $\mathrm{Mn}$ lattice in the basal plane also increases very slightly with the shortest Mn-Mn distance (2.8877(3) Å) which is slightly longer than in $\mathrm{CuMnO}_{2}(2.8876(8) \AA)$ and also the two longest distances $(3.1532(1) \AA)$ are larger than in $\mathrm{CuMnO}_{2}(3.1531(5) \AA)$. At room temperature, the $\mathrm{Cu}-\mathrm{O}$ distances also slightly vary by the substitution, close to $1.8392(5) \AA$ in $\mathrm{CuMnO}_{2}$ and to $1.8470(1) \AA$ in $\mathrm{CuMn}_{0.95} \mathrm{Fe}_{0.05} \mathrm{O}_{2}$.

We have also measured the neutron diffraction at $6 \mathrm{~K}$ for both $\mathrm{CuMnO}_{2}$ and $\mathrm{CuMn}_{0.95} \mathrm{Fe}_{0.05} \mathrm{O}_{2}$. In Fig. 3 we have shown the neutron diffraction pattern of $\mathrm{CuMn}_{0.95} \mathrm{Fe}_{0.05} \mathrm{O}_{2}$. On lowering the sample temperature superlattice reflections in both these compounds are observed indicating the antiferromagnetic nature of these compounds. On lowering of temperature we do not observe the splitting of the (220) reflection (the splitting of which indicates the transition from monoclinic to triclinic structure).$^{15} \mathrm{~A}$ marginal improvement in the fit is obtained in the triclinic phase but we have analysed the diffraction in the monoclinic structure in $C 2 / m$ space group at $6 \mathrm{~K}$. The cell parameters of Fe doped $\mathrm{CuMnO}_{2}(a=5.5582(4) \AA$, $b=2.8850(2) \AA, c=5.8986(4) \AA, \beta=104.230(7))$, significantly differ from those of $\mathrm{CuMnO}_{2}(a=5.5675(5) \AA, b=2.8759(2) \AA$, $c=5.8811(5) \AA, \beta=104.058(1))$. Compared to RT, the difference in the cell volume is more at low temperature (LT) in Fe doped $\mathrm{CuMnO}_{2}$. In this low temperature structure, the oxygen atoms occupy a general symmetry lattice site $(x, y, z)$ and the oxygen position at low temperature also varies with Fe doping. Dealing with the triangular Mn-array in the $(a, b)$ plane, the $\mathrm{Mn}-\mathrm{Mn}$ shortest edge of the triangle is slightly elongated (from $2.8759 \AA$ along [010] to $2.8850 \AA$ along [110]). In the $\mathrm{MnO}_{6}$ octahedron at low temperature, the two long apical $\mathrm{Mn}-\mathrm{O}$ distances are $2.2574 \AA$, while the four equatorial distances are $(1.9278 \AA$ ). While, for $\mathrm{CuMnO}_{2}$ in the $\mathrm{MnO}_{6}$ octahedron at low temperature, the apical Mn-O distances are $2.2618 \AA$, and the equatorial distances are $1.9277 \AA$ indicating that Fe doping decreases the distortion in $\mathrm{MnO}_{6}$ octahedra. For nonstoichiometric $\mathrm{Cu}_{1.04} \mathrm{Mn}_{0.96} \mathrm{O}_{2}$ sample also the distortion in $\mathrm{MnO}_{6}$ octahedra is decreased. ${ }^{10}$ Therefore, no change in the chemical structure is

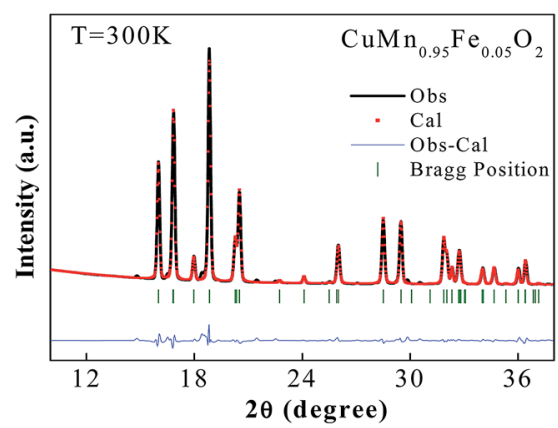

Fig. 1 Rietveld refinement of synchrotron $X$-ray powder diffraction data of $\mathrm{CuMn}_{0.95} \mathrm{Fe}_{0.05} \mathrm{O}_{2}$ at room temperature. 


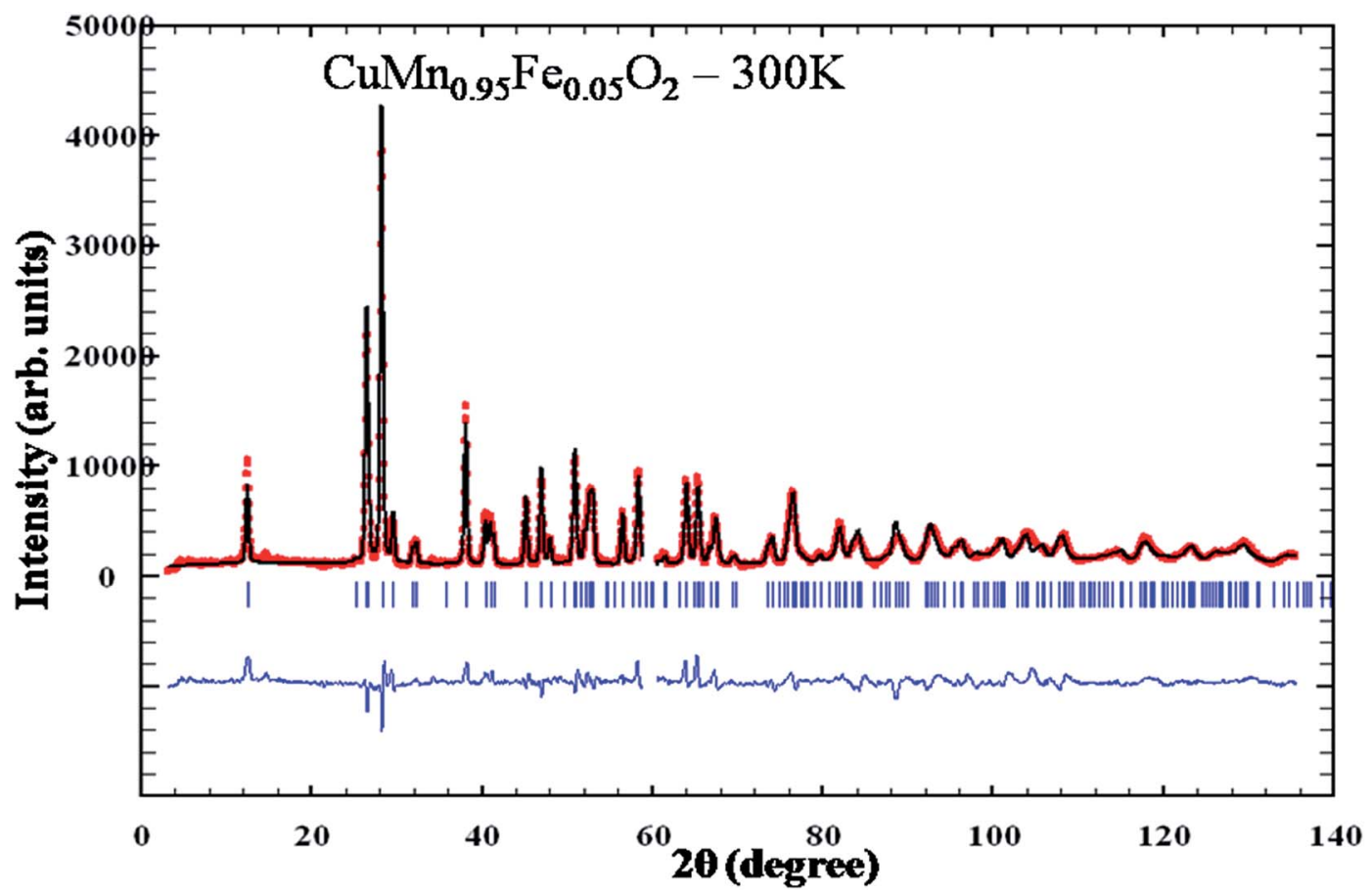

Fig. 2 Rietveld refinement of neutron powder diffraction data of $\mathrm{CuMn}_{0.95} \mathrm{Fe}_{0.05} \mathrm{O}_{2}$ at room temperature.

observed on Fe doping, although the magnetic structure is found to be different on Fe doping. The structural parameters obtained from the analysis are summarized in Table 1. In the

Table 1 Rietveld refinement of room temperature synchrotron XRD of $\mathrm{CuMnO}_{2}$ and $\mathrm{CuMn}_{0.95} \mathrm{Fe}_{0.05} \mathrm{O}_{2}$

\begin{tabular}{lll}
\hline Sample/parameters & $\mathrm{CuMnO}_{2}, 300 \mathrm{~K}$ & $\mathrm{CuMn}_{0.95} \mathrm{Fe}_{0.05} \mathrm{O}_{2}, 300 \mathrm{~K}$ \\
\hline Space group & $C 2 / m$ & $C 2 / m$ \\
Cell parameters & & \\
$a(\AA)$ & $5.6063(3)$ & $5.6064(3)$ \\
$b(\AA)$ & $2.8876(8)$ & $2.8877(3)$ \\
$c(\AA)$ & $5.8990(3)$ & $5.8990(3)$ \\
Cell volume $(\AA)^{3}$ & 92.6774 & 92.6823 \\
$\alpha$ (deg) & 90 & 90 \\
$\beta$ (deg) & $103.965(3)$ & $103.961(3)$ \\
$\gamma($ deg) & 90 & 90
\end{tabular}

$\begin{array}{lll}\text { Atomic positions } & & \\ \mathrm{O}(4 \mathrm{i}) x & 0.4073 & 0.39978 \\ y & 0 & 0 \\ z & 0.17890 & 0.17789\end{array}$

\section{Occupancy}

(

\section{$\mathrm{Mn}$}

Fe

Mn-Mn

\section{$\mathrm{Cu}-\mathrm{O}$}

Bragg $R$ factor

$R_{\mathrm{F}}$

$R_{\mathrm{P}}$

$R_{\mathrm{wp}}$
$X^{2}$

1
1
$2.8876(8) \times 2$
$3.1531(5) \times 4$
$1.8392(5) \times 2$
4.139
2.601
9.70
10.09
2.44

1

0.95

0.05

$2.8877(3) \times 2$

$3.1532(1) \times 4$

$1.8470(1) \times 2$

2.886

2.101

8.07

9.72

1.98 case of $\mathrm{CuMnO}_{2}$ the superlattice reflections were indexed using the two propagation vectors $\boldsymbol{k}_{1}=(1 / 2 \cdot 1 / 2 \cdot 1 / 2)$ and $\boldsymbol{k}_{2}=$ $(1 / 2 \cdot 1 / 2 \cdot 0)$. The intensities corresponding to $\boldsymbol{k}_{2}$ were very weak in agreement with Damay et al., ${ }^{8}$ but not absent as reported previously in this compound. ${ }^{16}$ The magnetic structure described by $\boldsymbol{k}_{1}$ consists of antiferromagnetic chains in the $(a, b)$ plane coupled antiferromagnetically along the $c$-axis. The components of the moment are $3.2 \mu_{\mathrm{B}}$ and $1.9 \mu_{\mathrm{B}}$ along $a$ and $c$-axes corresponding to $3.3 \mu_{\mathrm{B}}$. For $\boldsymbol{k}_{2}$ vector the magnetic

Table 2 Rietveld refinement of the neutron powder diffraction data for $\mathrm{CuMnO}_{2}$ and $\mathrm{CuMn}_{0.95} \mathrm{Fe}_{0.05} \mathrm{O}_{2}$ at $6 \mathrm{~K}$

\begin{tabular}{lll}
\hline Sample/parameters & $\mathrm{CuMnO}_{2}, 6 \mathrm{~K}$ & $\begin{array}{l}\mathrm{CuMn}_{0.95} \mathrm{Fe}_{0.05} \mathrm{O}_{2}, \\
6 \mathrm{~K}\end{array}$ \\
\hline Space group & $C 2 / m$ & $C 2 / m$ \\
& & \\
Cell parameter & & \\
$a(\AA)$ & $5.5675(5)$ & $5.5582(4)$ \\
$b(\AA)$ & $2.8759(2)$ & $2.8850(2)$ \\
$c(\AA)$ & $5.8811(5)$ & $5.8986(4)$ \\
Cell volume $(\AA)^{3}$ & 91.3454 & 91.6842 \\
$\alpha(\mathrm{deg})$ & 90 & 90 \\
$\beta$ (deg) & 104.058 & $104.230(7)$ \\
$\gamma(\mathrm{deg})$ & 90 & 90
\end{tabular}

Atomic positions

$\begin{array}{lll}\mathrm{O}(4 \mathrm{i}) x & 0.4081(5) & 0.4087(5) \\ y & 0 & 0 \\ z & 0.1802(4) & 0.1790(4) \\ \mathrm{Mn}-\mathrm{O}^{\prime} & 2.2618(\times 2) & 2.2574(\times 2) \\ \mathrm{Mn}-\mathrm{O}^{\prime \prime} & 1.9277(\times 4) & 1.9278(\times 4) \\ \mathrm{Mn}-\mathrm{Mn} & 3.1332(\times 4) & 3.1312(\times 4) \\ & 2.8759(\times 2) & 2.8850(\times 2)\end{array}$




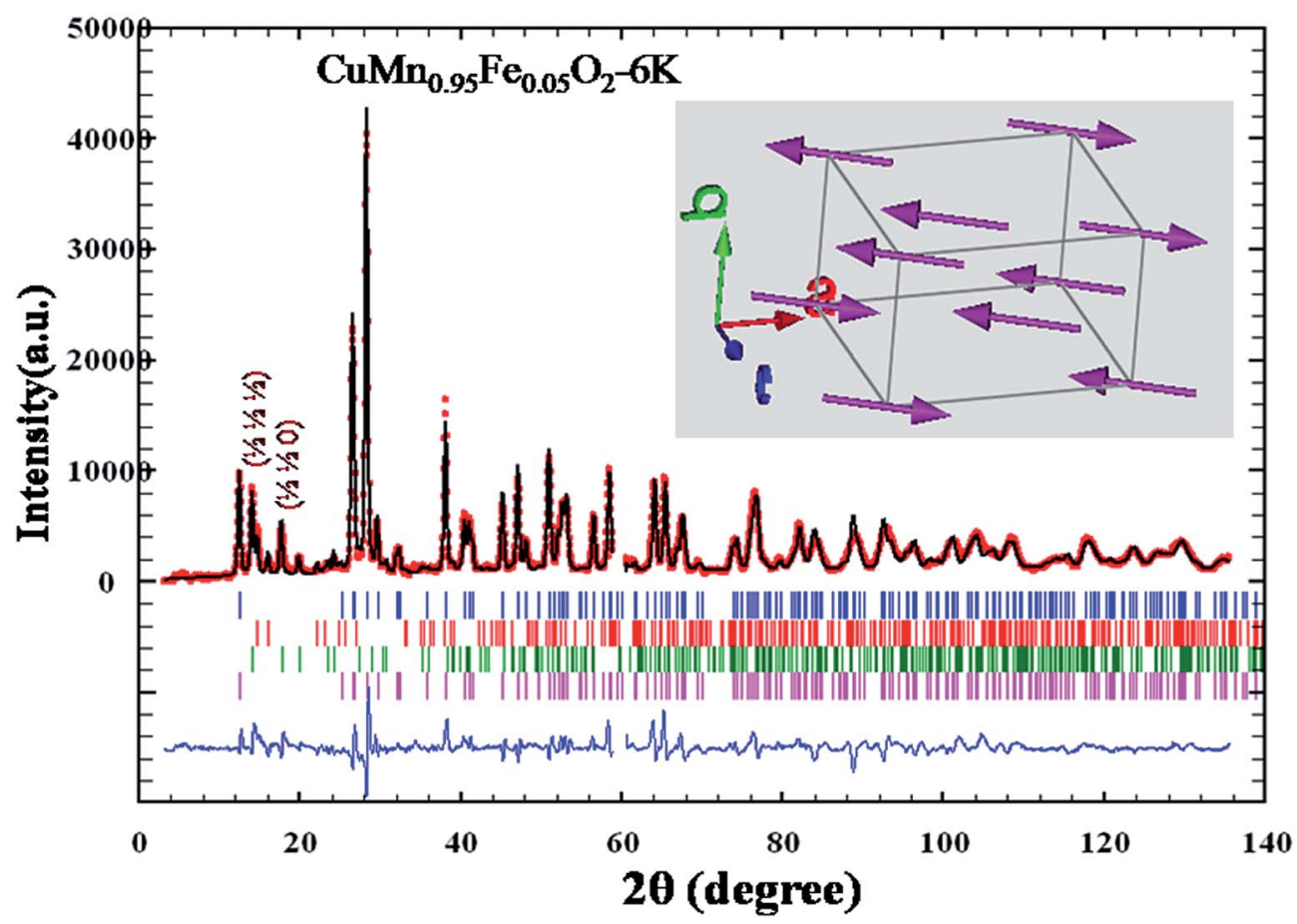

Fig. 3 Rietveld refinement of neutron powder diffraction data of $\mathrm{CuMn}_{0.95} \mathrm{Fe}_{0.05} \mathrm{O}_{2}$ at $6 \mathrm{~K}$.

moment is $0.9(3) \mu_{\mathrm{B}}$ and oriented along $c$-axis. The total moment is lower than the expected moment of $4 \mu_{\mathrm{B}}$ for $\mathrm{Mn}^{3+}$ in high spin state. Fe is found to substitute at the $\mathrm{Mn}$ site. It results in a large increase in the intensity of $(1 / 2 \cdot 1 / 2 \cdot 0)$ reflection corresponding to $\boldsymbol{k}_{2}$. The moment oriented along $a$ and $c$ are 2.4 $\mu_{\mathrm{B}}$ and $2.0 \mu_{\mathrm{B}}$, respectively leading to a total moment of $2.7 \mu_{\mathrm{B}}$. The moment corresponding to $\boldsymbol{k}_{1}$ vector is $1.8 \mu_{\mathrm{B}}$. A net increase in the moment $\left(4.5 \mu_{\mathrm{B}}\right)$ is observed as expected for a mixture of $\mathrm{Mn}^{3+}\left(4 \mu_{\mathrm{B}}\right)$ and $\mathrm{Fe}^{3+}\left(5 \mu_{\mathrm{B}}\right)$, which is nearly equal to the saturation value of the $\mathrm{Cu}(\mathrm{Mn}, \mathrm{Fe}) \mathrm{O}_{2}$ sample. The appearance of $\boldsymbol{k}_{2}$ propagation vector indicates the ferromagnetic coupling between $a b$ planes.

\section{Optical properties}

We have also studied the electronic structure of $\mathrm{CuMnO}_{2}$ and $\mathrm{CuMn}_{0.95} \mathrm{Fe}_{0.05} \mathrm{O}_{2}$ using X-ray photoemission spectroscopy (XPS). The purpose of this study was to investigate any role of the electronic structure on the magnetic properties of $\mathrm{CuMnO}_{2}$. The XPS core level spectra of $\mathrm{Cu} 2 \mathrm{p}, \mathrm{Mn} 2 \mathrm{p}$ and $\mathrm{Fe} 2 \mathrm{p}$ and $\mathrm{O} 1 \mathrm{~s}$ are shown in Fig. 4(a-d). Fig. 4(a) shows high resolution spectra of $\mathrm{Cu} 2 \mathrm{p}$ core level. Two clear distinct states of $\mathrm{Cu}\left(2 \mathrm{p}_{3 / 2}\right)$ at $952 \mathrm{eV}$ and $\mathrm{Cu}\left(2 \mathrm{p}_{1 / 2}\right)$ at $932 \mathrm{eV}$ are separated by $19.75 \mathrm{eV}$ and $19.9 \mathrm{eV}$ for $\mathrm{CuMnO}_{2}$ and $\mathrm{CuMn}_{0.95} \mathrm{Fe}_{0.05} \mathrm{O}_{2}$, respectively. Fig. 4(b) shows core level spectra of Mn2p. Two separate states of $\mathrm{Mn}\left(2 \mathrm{p}_{3 / 2}\right)$ and $\mathrm{Mn}\left(2 \mathrm{p}_{1 / 2}\right)$ observed at $641.6 \mathrm{eV}$ and $652.95 \mathrm{eV}$ for $\mathrm{CuMnO}_{2}$ and $641.3 \mathrm{eV}$ and $652.9 \mathrm{eV}$ for $\mathrm{CuMn}_{0.95} \mathrm{Fe}_{0.05} \mathrm{O}_{2}$, respectively. Fig. 4(c) exhibit Fe2p core level spectra of $\mathrm{CuMn}_{0.95} \mathrm{Fe}_{0.05} \mathrm{O}_{2}$ compound which shows the spin-orbit splitting of the Fe2p level, manifested as $\mathrm{Fe} 2 \mathrm{p}_{3 / 2}$ and $\mathrm{Fe} 2 \mathrm{p}_{1 / 2}$. The difference between these two Fe peaks is $13.5 \mathrm{eV}$, which confirms the presence of
$\mathrm{Fe}^{3+}$ state. These observed doubly states are due to the spinorbit coupling. Slight shifting in the states with Fe doping occurs due to change in interaction energy between $\mathrm{Cu}$ and transition metal ion. These data clearly suggest that $\mathrm{Cu}$ is in +1 state and both $\mathrm{Mn}$ and Fe are in +3 state. Fig. 4(d) shows the spectra of oxygen which has two peak structures. Two peaks marked as X observed at $529.8 \mathrm{eV}$ and $529.6 \mathrm{eV}$ and $\mathrm{Y}$ at 531.55 $\mathrm{eV}$ and $531.1 \mathrm{eV}$ for $\mathrm{CuMnO}_{2}$ and $\mathrm{CuMn}_{0.95} \mathrm{Fe}_{0.05} \mathrm{O}_{2}$, respectively. The first peak marked as $\mathrm{X}$, is characteristic peak of " $\mathrm{O}^{2-\text { " }}$ ions of the lattice oxygen, while peak $\mathrm{Y}$ denotes $\mathrm{O}(1 \mathrm{~s})$ lateral structure. This lateral peak corresponds to the ionizations of weakly adsorbed species ${ }^{17}$ and also the ionizations of oxygen ions with particular coordinates, more specifically integrated in the subsurface. This suggests that the existence, in the subsurface of oxygen ions that bear lower electron density than

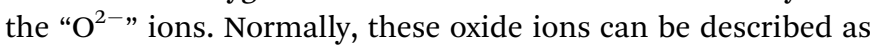
" $\mathrm{O}^{-}$" species or excess oxygen. When the density of lattice oxygen varies, the area ratio of these two peaks i.e. $\mathrm{X}$ and $\mathrm{Y}$ also changes. Valence level spectra of $\mathrm{CuMnO}_{2}$ and $\mathrm{CuMn}_{0.95} \mathrm{Fe}_{0.05}$ $\mathrm{O}_{2}$ samples are shown in Fig. 5. Four features (A, B, C, D) can be identified in the experimental spectra of both the samples. Feature A relate to state of dominant $\mathrm{Cu} 3 \mathrm{~d}$ atomic character while $\mathrm{B}$ and $\mathrm{C}$ relate to the hybridization with $\mathrm{Cu} 3 \mathrm{~d}$ and $\mathrm{Mn} 3 \mathrm{~d}$ to $\mathrm{O} 2 \mathrm{p} .{ }^{18}$ Feature D is a tail like structure near the Fermi level, $E_{\mathrm{F}}$. The electronic states near the Fermi level are mostly responsible for the electronic properties. A comparison of the valence band spectra for the two samples reveals that the density of states is negligibly small but finite at $E_{\mathrm{F}}$ which is clear from the inset of Fig. 5. The density of states slightly increases with Fe doping. Therefore, conductivity increases slightly with Fe doping. The XRD and neutron diffraction data also support 

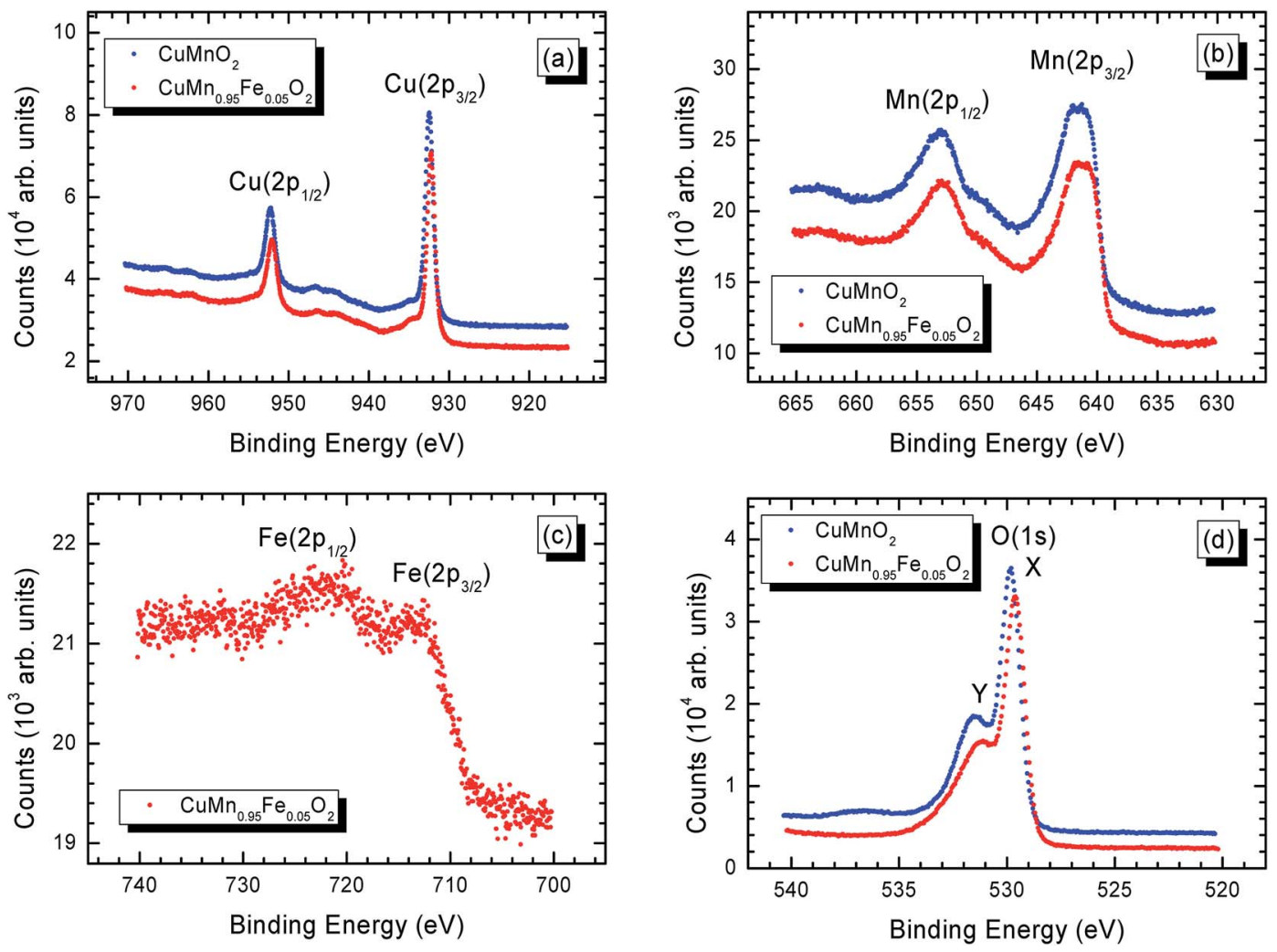

Fig. 4 XPS core level spectra of (a) Cu2p (b) Mn2p (c) Fe2p and (d) O1s [(

blue dots for $\mathrm{CuMnO}_{2}$ and red dots

for $\left.\mathrm{CuMn} 0.95 \mathrm{Fe}_{0.05} \mathrm{O}_{2}\right]$

this. It is observed from Table 1 that on Fe doping $\mathrm{Cu}-\mathrm{O}$ bond length increases and $\mathrm{Mn}-\mathrm{O}$ bond length decreases. This will lead to the increase of bandwidth and as a consequence band gap will decrease. ${ }^{\mathbf{1 8}}$ Moreover, it has been observed (Table 1) that on Fe doping the $c$ axis is elongated leading to weaker $\mathrm{Cu} 3 \mathrm{~d}-\mathrm{O} 2 \mathrm{p}$ hybridization. In the valence band spectra (Fig. 5) also it is found that in $\mathrm{CuMn}_{0.95} \mathrm{Fe}_{0.05} \mathrm{O}_{2}$ the $\mathrm{B}$ and $\mathrm{C}$ features are reduced with respect to the $A$ feature in accordance with the XRD and neutron diffraction data (Table 1). It is worthwhile to mention that the valence band spectrum of $\mathrm{CuMnO}_{2}$ differs from that of $\mathrm{CuCrO}_{2}$ (ref. 19) in respect of non-existence of the shoulder at the upper part of the valence band indicating that Mn3d is located away from the Fermi level. The most interesting feature is the shift of Fermi level towards lower binding energy for both $\mathrm{CuMnO}_{2}$ and $\mathrm{CuMn}_{0.95} \mathrm{Fe}_{0.05} \mathrm{O}_{2}$ unlike $\mathrm{CuCrO}_{2} \cdot{ }^{18,19}$ Similar behavior is observed in $\mathrm{K}$ doped $\mathrm{SrCu}_{2} \mathrm{O}_{2} \cdot{ }^{20}$ This shift is related to low activation energy of $\mathrm{CuMnO}_{2}$. Furthermore, with Fe doping it is observed that shift in Fermi energy is slightly larger than that in undoped sample. This is close to the further change in activation energy. Therefore, the photo emission spectroscopy measurements confirm the movement of Fermi level towards the valence band edge on Fe doping which is accompanied by corresponding shifts in core level binding energies. Similar kind of movement is observed in $\mathrm{CuCrO}_{2}$ with $\mathrm{Mg}$ doping. ${ }^{20}$ In the present investigation the $\mathrm{Cu} 2 \mathrm{p}_{3 / 2}$ peak shifts with Fe doping from $932.45 \mathrm{eV}$ to $932.2 \mathrm{eV}$.

The absorption curves of $\mathrm{CuMnO}_{2}$ and Fe doped $\mathrm{CuMnO}_{2}$ are shown in Fig. 6. As the photon energy increases the absorption intensity increases and attains a maximum. For the undoped sample the maximum occurs at $E=4.2 \mathrm{eV}$ whereas for the Fe doped sample it increases to $4.5 \mathrm{eV}$. The peak can be assigned to

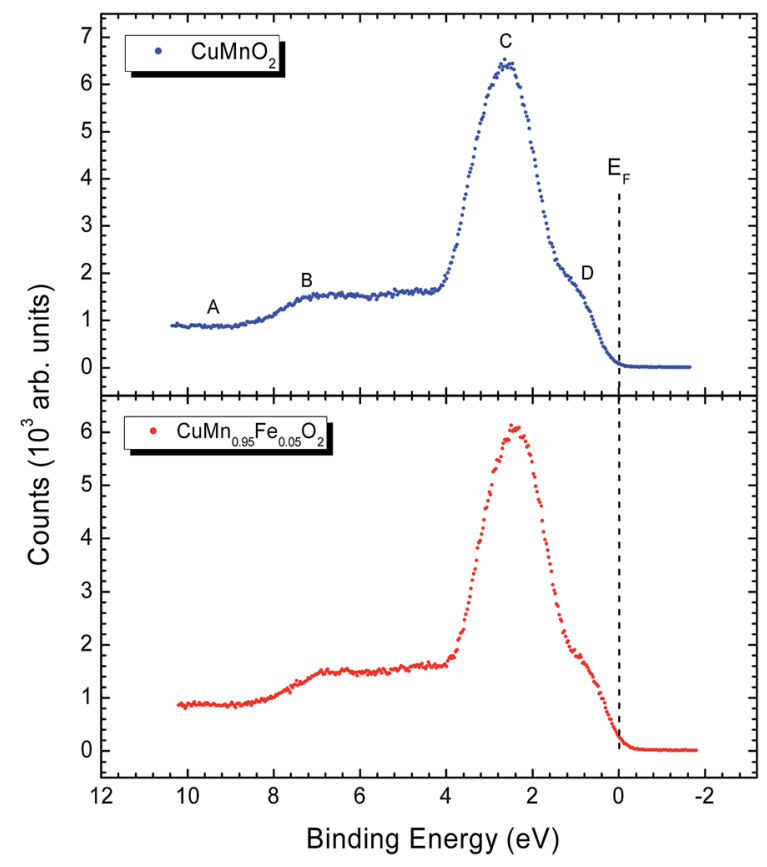

Fig. 5 Valance-band XPS spectra of $\mathrm{CuMnO}_{2}$ and $\mathrm{CuMn} \mathrm{n}_{0.95} \mathrm{Fe}_{0.05} \mathrm{O}_{2}$ $\left[(\bullet)\right.$ blue dots for $\mathrm{CuMnO}_{2}$ and red dots $(\mathbf{O})$ for $\left.\mathrm{CuMn}_{0.95} \mathrm{Fe}_{0.05} \mathrm{O}_{2}\right]$. 
an excitonic excitation from $\mathrm{Cu} 3 \mathrm{~d}+\mathrm{O} 2 \mathrm{p}$ to $\mathrm{Cu} 3 \mathrm{~d}+4 \mathrm{~s} \cdot{ }^{\mathbf{1 9 , 2 0}}$ For the Fe doped sample the peak intensity becomes negligibly small, the reason of which is not yet clear. It deserves further study. Moreover, the optical band gaps result from the relationship between the optical absorption coefficient and the photon energy $(h \nu)$ can be expressed as:

$$
(\alpha h \nu)^{2}=A\left(h \nu-E_{\mathrm{g}}\right)
$$

where $A$ is a constant and $E_{\mathrm{g}}$ is the direct optical band gap of the material. The inset of Fig. 6 shows the optical band gap of the undoped and Fe doped $\mathrm{CuMnO}_{2}$. It is observed from the figure that both samples have two energy band gaps. The band gaps of the crednerite $\mathrm{CuMnO}_{2}\left(4.60 \mathrm{eV}\right.$ and $4.90 \mathrm{eV}$ ) and $\mathrm{CuMn}_{0.95^{-}}$ $\mathrm{Fe}_{0.05} \mathrm{O}_{2}(4.60 \mathrm{eV}$ and $4.79 \mathrm{eV})$ are close to each other. Therefore, for both the samples an additional energy level exists near the valence band edge, as also revealed by valence band spectra (Fig. 5). The difference between the new band and the conduction band is $4.60 \mathrm{eV}$ for both the samples. On the other hand, the new band resides $0.30 \mathrm{eV}$ and $0.19 \mathrm{eV}$ above the top of the valence band respectively for $\mathrm{CuMnO}_{2}$ and $\mathrm{CuMn}_{0.95} \mathrm{Fe}_{0.05} \mathrm{O}_{2}$. Similar, new band is observed in $\mathrm{CuGa}_{0.8} \mathrm{Cr}_{0.2} \mathrm{O}_{2}$ film. ${ }^{21}$ Appearance of new band might be the reason of the shifting of Fermi level towards the valence band edge observed in valence band spectra (Fig. 5). Moreover, observed band gaps of these systems come in the range of wide band gap semiconductors and these values are even more than the band gap of $\mathrm{ZnO}(3.37 \mathrm{eV})$ and $\mathrm{GaN}$ (3.44 eV). ${ }^{22-24}$ Additionally, these systems show much better magnetic ordering and magnetic moment than any known diluted magnetic semiconductors, which might prove significant in the application of these materials as magnetic semiconductors.

\section{Electrical properties}

In order to understand the intrinsic characteristic, we have also studied the temperature dependence of resistivity for both $\mathrm{CuMnO}_{2}$ and $\mathrm{CuMn}_{0.95} \mathrm{Fe}_{0.05} \mathrm{O}_{2}$ compounds. The exponential decrease in resistivity with the increase in temperature indicates the semiconducting nature of both the samples. The plot of $\ln \rho$ versus $1000 / \mathrm{T}$ (Fig. 7) shows that thermally activated band

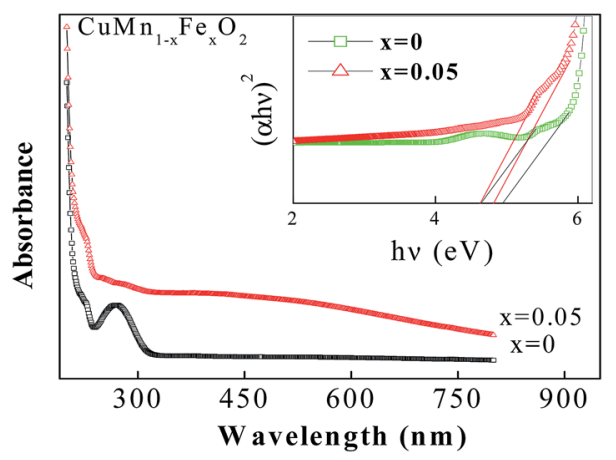

Fig. 6 Absorption spectra of $\mathrm{CuMnO}_{2}$ and $\mathrm{CuMn}_{0.95} \mathrm{Fe}_{0.05} \mathrm{O}_{2}$. Inset: optical band gap from UV-Visible spectroscopic measurement of $\mathrm{CuMnO}$ and $\mathrm{CuMn}_{0.95} \mathrm{Fe}_{0.05} \mathrm{O}_{2}$. conduction is the dominant mechanism at high-temperature region. The thermally activated resistivity at high-temperature region follows the Arrhenius law

$$
\rho(T)=\rho_{0} \exp \left[E_{\mathrm{a}} / k_{\mathrm{B}} T\right]
$$

where $k_{\mathrm{B}}$ is the Boltzmann's constant and $E_{\mathrm{a}}$ is the activation energy. The deviation from the linear fit indicates that thermal activation mechanism is not valid at lower temperature region. The variable-range-hopping (VRH) conduction of polarons has been found to dominate in this temperature region. The conduction mechanism due to the variable range hopping of polaron at low temperature can be described by the Mott's equation $^{25}$

$$
\rho(T)=\rho_{0} \exp \left[T_{0} / T\right]^{1 / 4}
$$

where $\rho_{0}$ and $T_{0}$ are constants and are given by $\rho_{0}=\left\{\left[8 \pi \alpha k_{\mathrm{B}} T /\right.\right.$ $\left.\left.N\left(E_{\mathrm{F}}\right)\right]^{1 / 2}\right\} /\left(3 \mathrm{e}^{2} \nu_{\mathrm{ph}}\right)$ and $T_{0}=18 \alpha^{3} /\left[k N\left(E_{\mathrm{F}}\right)\right]$ where $\nu_{\mathrm{ph}}\left(\sim 10^{13} \mathrm{~s}^{-1}\right)$ is the phonon frequency at Debye temperature, $N\left(E_{\mathrm{F}}\right)$ is the density of localized electron states at the Fermi level, and $\alpha$ is the inverse localization length. For $\mathrm{CuMnO}_{2}$ two slopes are observed which can be fitted with the eqn (1). The estimated activation energy $\left(E_{\mathrm{a}}\right)$ from the two slopes are $0.29 \mathrm{eV}$ and $0.96 \mathrm{eV}$. The estimated activation energy $\left(E_{\mathrm{a}}\right)$ for $\mathrm{CuMn}_{0.95^{-}}$ $\mathrm{Fe}_{0.05} \mathrm{O}_{2}$ using Arrhenius law is $0.90 \mathrm{eV}$. Moreover, we did not get proper fitting with the eqn (2).

\section{Magnetic properties}

Fig. 8 shows the magnetization of $\mathrm{CuMnO}_{2}$ as a function of magnetic field. At $5 \mathrm{~K}$, a clear hysteresis with a coercive field of $2.46 \mathrm{kOe}$ is observed. The magnetization increases almost linearly with magnetic field after closing of the hysteresis. The magnetic properties of $\mathrm{CuMnO}_{2}$ are controversial. ${ }^{26,27}$ Our data match with the data in ref. 19. The data indicate the presence of the dominating AFM order with some FM ordering. The AFM

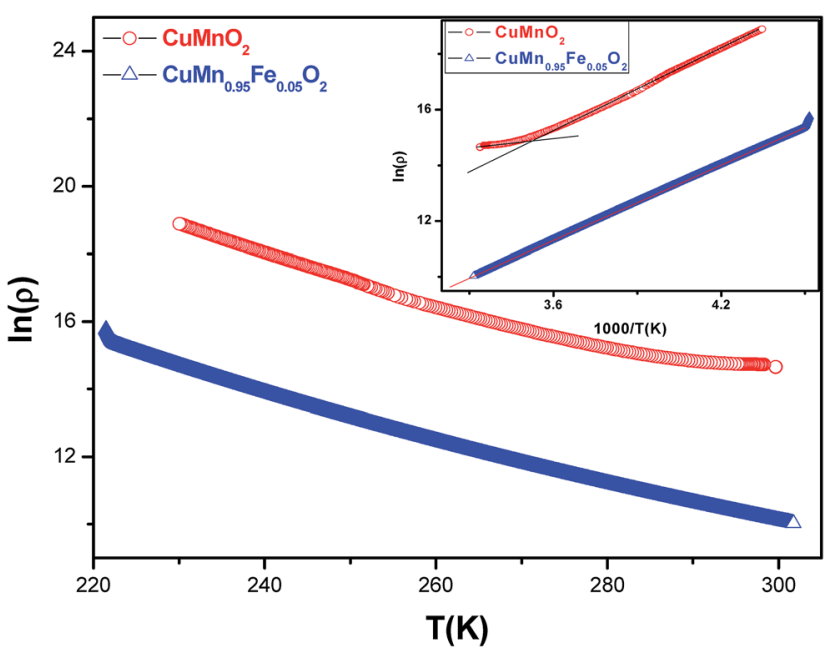

Fig. 7 Variation of resistivity versus temperature for $\mathrm{CuMn}_{1-x} \mathrm{Fe}_{x} \mathrm{O}_{2}$ (where $x=0,0.05)$. Inset variation of $\ln \rho$ vs. $1000 / T$ for $(x=0$ and 0.05) samples. 


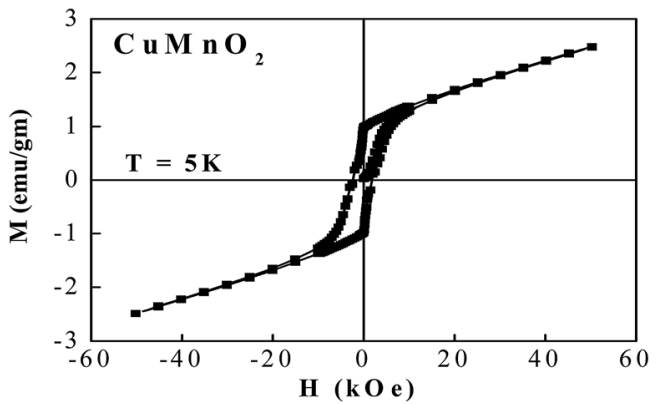

Fig. 8 Magnetization curve $\mathrm{M}(\mathrm{H})$ of $\mathrm{CuMnO}_{2}$ at $5 \mathrm{~K}$.

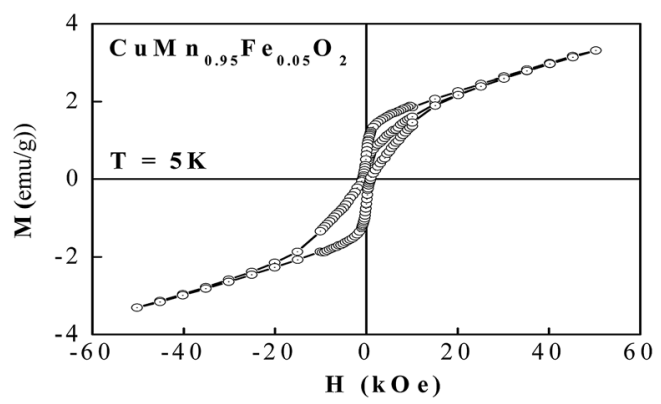

Fig. 9 Magnetization curve $M(H)$ of $\mathrm{CuMn}_{0.95} \mathrm{Fe}_{0.05} \mathrm{O}_{2}$ at $5 \mathrm{~K}$.

ordering at $50 \mathrm{~K}$ has also been reported recently by Kurakawa et al. ${ }^{28}$ The increase of high field magnetization along with the appearance of $H_{\mathrm{c}}$ indicates the emergence of an uncompensated moment. When Fe is doped (Fig. 9), the magnetization is increased but the coercivity is decreased. With increase of the magnetic field the ferromagnetic correlation precipitates and the antiferromagnetic correlation is increased which is clear from the $M(H)$ curve. The change in magnetic behavior with Fe doping can be explained in terms of magnetic exchanges, direct $\mathrm{Mn}-\mathrm{Mn}$ interactions may be considered as dominant in-plane but indirect exchanges (via oxygen) could also play a role, all $\mathrm{Mn}-\mathrm{O}-\mathrm{Mn}$ angles being close to $90^{\circ}$. The super-super exchange, along $\mathrm{Mn}-\mathrm{O}-\mathrm{Cu}-\mathrm{O}-\mathrm{Mn}$ path ways, may also play the role for the 3D magnetic ordering. In fact super-super exchange via diamagnetic cation is quite common, as is observed in different oxides. ${ }^{11}$ The difference in magnetic behavior with Fe doping might be due to the presence of $\boldsymbol{k}_{2}=(1 / 2 \cdot 1 / 2 \cdot 0)$ vector which has been observed from neutron diffraction measurement. As has been mentioned that the appearance of $\boldsymbol{k}_{2}=(1 / 2 \cdot 1 / 2 \cdot 0)$ vector is the indication of ferromagnetic coupling between $a b$ planes implying that $\mathrm{Fe}$ doping induces this ferromagnetic coupling. Similar behavior is observed in the nonstoichiometric $\mathrm{Cu}_{1.04} \mathrm{Mn}_{0.96} \mathrm{O}_{2}{ }^{10}$

\section{Conclusion}

Neutron diffraction, synchrotron X-ray diffraction, XPS, magnetic and UV-Visible spectroscopic measurements have been investigated on $\mathrm{CuMnO}_{2}$ and $5 \% \mathrm{Fe}$ doped $\mathrm{CuMnO}_{2}$ samples, with assumption that these measurements have complementary information on structural and magnetic behaviour of the samples. On Fe doping, the apical Mn-O distances decrease while the equatorial distances slightly increase, reducing the distortion in $\mathrm{MnO}_{6}$ octahedra. Moreover, when Fe is doped along with $\boldsymbol{k}_{1}=(1 / 2 \cdot 1 / 2 \cdot 1 / 2)$ the magnetic peaks can also be indexed with the propagation vector $\boldsymbol{k}_{2}=$ $(1 / 2 \cdot 1 / 2 \cdot 0)$ indicating the appearance of ferromagnetic coupling between $a b$ planes. Value of magnetization is increased with Fe doping but coercivity is decreased. These might be due to direct $\mathrm{Mn}-\mathrm{Mn}$ exchange and $\mathrm{Mn}-\mathrm{O}-\mathrm{Cu}-\mathrm{O}-\mathrm{Mn}$ super-super exchange interactions. The UV-Vis data showed the increase in one of the two energy gaps, on Fe doping, indicating the usefulness of these materials as wide band gap magnetic semiconductors.

\section{Acknowledgements}

S.C. is grateful to BRNS, DAE, India (Grant No.: 2013/37P/43/ BRNS) for providing financial support. P.S. is grateful to CSIR, India for providing financial support. Authors are also grateful to D. Budhikot for his help in magnetization measurement.

\section{References}

1 T. Kimura, T. Goto, H. Shintani, K. Ishizaka, T. Arima and Y. Tokura, Magnetic control of ferroelectric polarization, Nature, 2003, 426, 55-58.

2 N. Hur, S. Park, P. A. Sharma, J. S. Ahn, S. Guha and S. W. Cheong, Electric polarization reversal and memory in a multiferroic material induced by magnetic fields, Nature, 2004, 429, 392-395.

3 T. Lottermoser, T. Lonkai, U. Amann, D. Hohlwein, J. Ihringer and M. Fiebig, Magnetic phase control by an electric field, Nature, 2004, 430, 541-544.

4 A. J. W. Reitsma, L. F. Feiner and A. M. Oles, Orbital and spin physics in $\mathrm{LiNiO}_{2}$ and $\mathrm{NaNiO}_{2}$, New J. Phys., 2005, 7, 121.

5 F. Ye, J. A. Fernandez-Baca, R. S. Fishman, Y. Ren, H. J. Kang, Y. Qiu and T. Kimura, Magnetic Interactions in the Geometrically Frustrated Triangular Lattice Antiferromagnet $\mathrm{CuFeO}_{2}$, Phys. Rev. Lett., 2007, 99, 157201.

6 D. J. Singh, Magnetic and electronic properties of $\mathrm{LiMnO}_{2}$, Phys. Rev. B: Condens. Matter Mater. Phys., 1997, 55, 309-312.

7 T. Jia, G. Guo Zhang and Z. Zeng, Orbitally relieved magnetic frustration in $\mathrm{NaVO}_{2}$, Phys. Rev. B: Condens. Matter Mater. Phys., 2009, 80, 045103.

8 F. Damay, M. Poienar, C. Martin, A. Maignan, J. RodriguezCarvajal, G. Andre and J. P. Doumerc, Spin-lattice coupling induced phase transition in the $S=2$ frustrated antiferromagnet $\mathrm{CuMnO}_{2}$, Phys. Rev. B: Condens. Matter Mater. Phys., 2009, 80, 094410.

9 A. V. Ushakov, S. V. Streltsov and D. I. Khomskii, Orbital structure and magnetic ordering in stoichiometric and doped crednerite $\mathrm{CuMnO}_{2}$, Phys. Rev. B: Condens. Matter Mater. Phys., 2009, 80, 094410.

10 M. Poienar, C. Vecchini, G. Andre, A. Daoud-Aladine, I. Margiolaki, A. Maignan, A. Lappas, L. Chapon, M. Hervieu, F. Damay and C. Martin, Substitution Effect 
on the Interplane Coupling in Crednerite: the $\mathrm{Cu}_{1.04} \mathrm{Mn}_{0.96} \mathrm{O}_{2}$ Case, Chem. Mater., 2011, 23, 85-94.

11 C. Vecchini, M. Poienar, F. Damay, O. Adamopoulos, A. Daoud-Aladine, A. Lappas, J. M. Perez-Mato, L. C. Chapon and C. Martin, Magnetoelastic coupling in the frustrated antiferromagnetic triangular lattice $\mathrm{CuMnO}_{2}$, Phys. Rev. B: Condens. Matter Mater. Phys., 2010, 82, 094404.

12 M. Trari, J. Topfer, P. Dordor, J. C. Grenier, M. Pouchard and J. P. Doumerc, Preparation and physical properties of the solid solutions $\mathrm{Cu}_{1+x} \mathrm{Mn}_{1-x} \mathrm{O}_{2}(0 \leq x \leq 0.2)$, J. Solid State Chem., 2005, 178, 2751-2758.

13 J. Topfer, M. Trari, P. Garavcreau, J. P. Chaminade and J. P. Z. Doumerc, Kristallografiya, 1995, 210, 184.

14 I. D. Kandrashev, Sov. Phys. Crystallogr., 1959, 3, 703.

15 V. Ovidiu Garlea, A. T. Savici and R. Jin, Tuning the magnetic ground state of a triangular lattice system $\mathrm{Cu}\left(\mathrm{Mn}_{1-x} \mathrm{Cu}_{x}\right) \mathrm{O}_{2}$, Phys. Rev. B: Condens. Matter Mater. Phys., 2011, 83, 172407.

16 Y. Shirako, H. Satsukawa, X. X. Wang, J. J. Li, Y. F. Guo, M. Arai, K. Yamaura, M. Yoshida, H. Kojitani, T. Katsumata, Y. Inaguma, K. Hiraki, T. Takahashi and M. Akaogi, Integer spin-chain antiferromagnetism of the 4d oxide $\mathrm{CaRuO}_{3}$ with post-perovskite structure, Phys. Rev. B: Condens. Matter Mater. Phys., 2011, 83, 17441.

17 G. Gusmano, G. Montesperelli, E. Traversa and G. Mattogno, Microstructure and electrical properties of $\mathrm{MgAl}_{2} \mathrm{O}_{4}$ thin films for humidity sensing, J. Am. Ceram. Soc., 1993, 76, 743-750.

18 D. Shin, J. S. Foord, D. J. Payne, T. Arnold, D. J. Aston, R. G. Egdell, K. G. Godinho, D. O. Scanlon, B. J. Morgan, G. W. Watson, E. Mugnier, C. Yaicle, A. Rougier, L. Colakerol, P. A. Glans, L. F. J. Piper and K. E. Smith, Comparative study of bandwidths in copper delafossites from x-ray emission spectroscopy, Phys. Rev. B: Condens. Matter Mater. Phys., 2009, 80, 233105.

19 T. Arnold, D. J. Payne, A. Bourlange, J. P. Hu, R. G. Egdell, L. F. J. Piper, L. Colakerol, A. D. Masi, P. A. Glans,
T. Learmonth, K. E. Smith, D. O. Scanlon, A. Walsh, B. J. Morgan and G. W. Watson, X-ray spectroscopic study of the electronic structure of $\mathrm{CuCrO}_{2}$, Phys. Rev. B: Condens. Matter Mater. Phys., 2009, 79, 075102.

20 C. C. B. Lynch, R. G. Egdell and D. S. L. Law, High resolution X-ray photoemission of $\mathrm{SrCu}_{2} \mathrm{O}_{2}$, Chem. Phys. Lett., 2005, 401, 223-226.

21 M. Han, K. Jiang, J. Zhang, W. Yu, Y. Li, Z. Hu and J. Chu, Structural, electronic band transition and optoelectronic properties of delafossite $\mathrm{CuGa}_{1-x} \mathrm{Cr}_{x} \mathrm{O}_{2}(0 \leq x \leq 1)$ solid solution films grown by the sol-gel method, J. Mater. Chem., 2012, 22, 18463-18470.

22 A. Mang, K. Reimann and S. Rubenacke, Band gaps, crystalfield splitting, spin-orbit coupling, and exciton binding energies in $\mathrm{ZnO}$ under hydrostatic pressure, Solid State Commun., 1995, 94, 251-254.

23 O. Madelung, Semiconductor basic data $2^{\text {nd }}$ review edition, Springer, Berlin, 1996.

24 S. Kumar, S. Chatterjee, K. K. Chattopadhyay and A. K. Ghosh, Sol-gel derived ZnO: Mn nanocrystals: study of structural, Raman and optical properties, J. Phys. Chem. C, 2012, 116, 16700-16708.

25 N. F. Mott, Conduction in glasses containing transition metal ions, J. Non-Cryst. Solids, 1968, 1, 1-17.

26 J. P. Doumerc, M. Trari, J. Topfer, L. Fournes, J. C. Greinier, M. Pouchard and P. Hagenmuller, Magnetic properties of the crednerite $\mathrm{CuMnO}_{2}$, Eur. J. Solid State Inorg. Chem., 1994, 31, 705-715.

27 Y. Bessekhouad, Y. Gabes, A. Bouguelia and M. Trari, The physical and photo electrochemical characterization of the crednerite $\mathrm{CuMnO}_{2}$, J. Mater. Sci., 2007, 42, 6469-6476.

28 A. Kurakawa, T. Yanoh, S. Yano and Y. Ichiyanagi, Preparation and Magnetic Properties of Multiferroic $\mathrm{CuMnO}_{2}$ Nanoparticles, J. Nanosci. Nanotechnol., 2014, 14, 2553-2556. 